\title{
The Role of Two-Dimensional Ultrasonography in the Diagnosis of Protrusion of Cervical Intervertebral Discs in Adolescents
}

\author{
Abdullaev R. Ya. ${ }^{1}$, Kalashnikov V. I. ${ }^{1}$, Ibragimova K. N. ${ }^{1}$, Mammadov I. G. ${ }^{1}$, Abdullaev R. R. ${ }^{2}$ \\ ${ }^{1}$ Department of Ultrasound Diagnostics, Kharkiv Medical Academy of Postgraduate Education, Kharkiv, Ukraine \\ ${ }^{2}$ Department of Radiology, Kharkiv Medical Academy of Postgraduate Education, Kharkiv, Ukraine
}

Email address:

r.abdullaev@bk.ru (Abdullaev R. Ya.), rizvanabdullaiev@gmail.com (Abdullaev R. Ya.)

\section{To cite this article:}

Abdullaev R. Ya., Kalashnikov V. I., Ibragimova K. N., Mammadov I. G., Abdullaev R. R. The Role of Two-Dimensional Ultrasonography in the Diagnosis of Protrusion of Cervical Intervertebral Discs in Adolescents. American Journal of Clinical and Experimental Medicine. Vol. 5, No. 5, 2017, pp. 176-180. doi: 10.11648/j.ajcem.20170505.14

Received: August 13, 2017; Accepted: August 25, 2017; Published: September 19, 2017

\begin{abstract}
Objective: To improve the efficiency of cervical intervertebral discs protrusion by determining the ultrasound biomarkers. Materials and Methods: The study included 72 healthy adolescents with normal intervertebral discs, 96 person with the degenerative changes in nucleus pulpous and 69 person with the disc protrusions. In axial section was performed the sagittal intervertebral disc and spinal canal sizes, the anterior dural space size, the width of spinal nerve canals. Results: The protrusion of the cervical discs in $11(15,9 \pm 4,4 \%)$ cases was noted in children aged 13-14 years, in $21(30,5 \pm 5,5 \%)$ - at $15-16$ years and in $37(53,6 \pm 6,0 \%)-$ at $17-18$ years $(\mathrm{p}<0,01$ and $\mathrm{p}<0,001$ respectively). In $24(34,8 \pm 5,7 \%)$ cases, the protrusion was localized at the level of $(34,8 \pm 5,7 \%)$, in $16(23,2 \pm 5,1 \%)$ - C4-C5, in $11(15,9 \pm 4,4 \%)$ - at the level C6-C7, in $9(13,0 \pm 4,0 \%)$ - at the level of C3-C4 respectively. In $26(37,7 \pm 5,8 \%)$ cases the protrusion had paramedian, in $18(26,1 \pm 5,3 \%)$ cases - medianparamedian, in $16(23,2 \pm 5,1 \%)$ cases - median, in $6(8,7 \pm 3,4)$ cases - circular, in $3(4,3 \pm 2,4)$ cases - posterolateral localization. In healthy children without degenerative changes of the intervertebral discs, the average sagittal disc size is $15,4 \pm 0,98 \mathrm{~mm}$, in a group with a change of the nucleus pulpous $-16,1 \pm 1,07 \mathrm{~mm}$, in a group with disc protrusion $-16,3 \pm 1,12 \mathrm{~mm}$, respectively. The parameters of average sagittal spinal size was $15,9 \pm 0,97 \mathrm{~mm}, 15,2 \pm 1,04 \mathrm{~mm}, 14,1 \pm 0,87 \mathrm{~mm}$, respectively. The IVD/SC index was $0,97 \pm 0,05,1,06 \pm 0,06,1,16 \pm 0,07$, respectively. The ADS was $3,7 \pm 0,45 \mathrm{~mm}, 3,2 \pm 0,38 \mathrm{~mm}, 2,1 \pm 0,26 \mathrm{~mm}$, and ADS/SC $0,23 \pm 0,026,0,21 \pm 0,019,0,15 \pm 0,017$ respectively. Conclusions: In adolescents in the cervical spine, median-paramedian and paramedian protrusions are most commonly found, which are most often localized at the level of both C5-C6 and C4-C5. The greatest narrowing and deformation of the anterior dural space is observed by median and median-paramedian protrusions, and the spinal nerve canal - by posterolateral and paramedian protrusions.
\end{abstract}

Keywords: Cervical Intervertebral Discs Protrusion, Spinal Canal, Ultrasound Diagnostics, Adolescents

\section{Introduction}

Cervical degenerative disc disease is a common cause of neck pain and radiating arm pain. It develops when one or more of the cushioning discs in the cervical spine starts to break down due to wear and tear. There may be a genetic component that predisposes some people to more rapid wear. Injury may also accelerate and sometimes cause the development of the degenerative changes. In children, the discs are about $85 \%$ water. The discs begin to naturally lose hydration during the aging process. Some estimates have the disc's water content typically falling to $70 \%$ by age 70 , but in some people the disc can lose hydration much more quickly. As the disc loses hydration, it offers less cushioning and becomes more prone to cracks and tears. [1].

Studies show that a plurality of adults have no symptoms related to degenerative disc disease, even though a high percentage of these adults still shows signs of disc degeneration on an MRI somewhere on the spine. One study found that about half of people start showing some signs of 
disc degeneration on an MRI by their early 20s [2].

When degenerative disc disease develops in the cervical spine, it can occur in any of the cervical discs but is slightly more likely to occur at the C5-C6 level [3]. A small-sample study examining the cervical spine in symptom-free volunteers has found focal disc protrusions in $50 \%$ of participants, which suggests that a considerable part of the population can have focal herniated discs in their cervical region that do not cause noticeable symptoms [4].

Traditional plain X-rays does not allow visualizing intervertebral discs, ligamentous apparatus of the spinal column. Currently, magnetic resonance imaging (MRI) is the main method of visualization of intervertebral discs, ligamentous apparatus, spinal cord however, considering the lower costs, accessibility, high resolution and real-time imaging, the ultrasonography can be the relevant alternative for screening [5].

Diagnostic ultrasound involves the use of high frequency sound waves (3-17 MHz) to image bony and soft tissue structures for the purposes of diagnosing pathology and or guiding real-time intervention procedures. Ultrasound is usually most effective with tissues that have high collagen content such as tendons, ligaments, joint capsules, and fascia. Pulsed modes tend to be used for acute inflammation versus a continuous mode for chronic inflammation [6 - 9]. Spinal ultrasonography has been used to investigate degenerative disc disease to determine whether back pain is a consequence of fissuring or herniation of the gelatinous discs that separate the vertebrae. Spinal ultrasound has also been used in the assessment of injuries to paraspinal ligaments after spinal fractures. Although ultrasonography has limited ability to reveal bone and tissues surrounding bone, it has been studied as a means to assess the posterior ligament complex that contributes to the maintenance of spinal stability $[10,11]$.

The American Institute of Ultrasound in Medicine (AIUM) Ultrasound Practice Accreditation Council has developed standards for the accreditation of ultrasound practices. These standards serve as a benchmark for ultrasound professionals seeking to meet nationally accepted protocols [12]. In previous studies, the herniated lumbar discs for screening programs in the late childhood and teenage are presented [13] Development of ultrasound semiotics of the cervical discs protrusion is an actual task.

Objective: To improve the efficiency of cervical intervertebral discs protrusion by determining the ultrasound biomarkers.

\section{Materials and Methods}

Ultrasound, X-ray and magnetic resonance imaging study 165 children with cervical pain observed in the pediatric neurologist and an orthopedic at the age of 13 to 18 years. All patients had clinical signs of degenerative disc disease and complained of cervicogenic paine. In the studied persons dominated the occipital localization of pain $(84.6 \%)$. The pulsating type of pain was observed in $17.4 \%$ of patients, bursting - in 62,9\%, their combination - in $19.7 \%$. Ultrasonography of the cervical spine held on the levels from C2-C3 to C7-Th1.

Changes in intervertebral discs were characterized followed:

- within the nucleus pulpous (NP);

- within the pulpous nucleus and fibrous ring (FC) without disturbing its integrity;

- Violation of the integrity of the fibrous ring with involvement in the pathological process of the spinal canal (SC).

Qualitative changes in the intervertebral discs were:

1) increased echogenicity of the nucleus pulpous;

2) the displacement of the nucleus pulpous;

3 ) increased echogenicity and thinning of the fibrous ring;

4) protrusion of the fibrous ring more than $2 \mathrm{~mm}$;

5) narrowing of anterior dural space or spinal nerve canals.

In 96 children the changes in the cervical discs were registered within the nucleus pulposus and in 69 children than offset the nucleus pulposus had abnormal fibrous ring in the form of non-uniform thinning posterior protrusion of up to $3 \mathrm{~mm}$. The comparative group consisted of 72 voluntary children who did not have disc changes and complaints. They made up the I group, those whose changes were only within the pulpous nucleus - the II group, and with protrusion of the discs - the III group.

\section{Results}

Among children with cervical discs protrusion in 11 $(15,9 \pm 4,4 \%)$ cases the age was at $13-14$ years, in 21 $(30,5 \pm 5,5 \%)$ - at $15-16$ years and in $37(53,6 \pm 6,0 \%)$ - at $17-$ 18 years. Statistical analysis showed the disc protrusion significantly more common among children aged $17-18$ years ( $\mathrm{p}<0,01$ and $\mathrm{p}<0,001$ respectively).

In $5(7,2 \pm 3,1 \%)$ cases the protrusion was localized at the level of $\mathrm{C} 2-\mathrm{C} 3$, in $9(13,0 \pm 4,0 \%)$ - at the level of $\mathrm{C} 3-\mathrm{C} 4$, in $16(23,2 \pm 5,1 \%)-\mathrm{C} 4-\mathrm{C} 5$, in $24(34,8 \pm 5,7 \%)-\mathrm{C} 5-\mathrm{C} 6$, in 11 $(15,9 \pm 4,4 \%)$ - at the level C6-C7, in $4(5,8 \pm 2,8 \%)$ - at the level C7 -Th1, respectively. There was demonstrated, that the cervical disc protrusion occurs significantly more frequently at the level of $\mathrm{C} 5-\mathrm{C} 6, \mathrm{C} 4-\mathrm{C} 5$ and $\mathrm{C} 6-\mathrm{C} 7$ respectively.

(Reject - We have studied the localization of protrusions). The localization of protrusions was studied. The median protrusion was observed - in $16(23,2 \pm 5,1 \%)$, medianparamedian - in $18(26,1 \pm 5,3 \%)$, paramedian - in 26 $(37,7 \pm 5,8 \%)$, circular protrusion - in $6(8,7 \pm 3,4)$, posterolateral - in $3(4,3 \pm 2,4)$ cases, respectively (table 1$)$. 
Table 1. Localization of protrusions in cervical intervertebral discs.

\begin{tabular}{llll}
\hline The type of protrusion & & Quantity, $\mathbf{n}=\mathbf{6 9}$ & $\mathbf{\%}$ \\
\hline 1 & Median & 16 & $23,2 \pm 5,1$ \\
2 & Median-paramedian & 18 & $26,1 \pm 5,3$ \\
3 & Paramedian & 26 & $37,7 \pm 5,8$ \\
4 & Circular & 6 & $8,7 \pm 3,4$ \\
5 & Posterolateral & 3 & $4,3 \pm 2,4$ \\
\hline
\end{tabular}

Table 2. Ultrasound parameters of IVD and SC of the cervical region in healthy adolescents

\begin{tabular}{llll}
\hline \multirow{2}{*}{ Ultrasonographic parameters } & $\begin{array}{l}\text { I group } \\
\text { The healthy children }(\mathbf{n}=\mathbf{7 2})\end{array}$ & $\begin{array}{l}\text { II group } \\
\text { The changes in the nucleus pulpous (n=96) }\end{array}$ & $\begin{array}{l}\text { III group } \\
\text { Discs protrusion (n=69) }\end{array}$ \\
\hline Sagittal size IVD, mm & $15,4 \pm 0,98$ & $16,1 \pm 1,07$ & $16,3 \pm 1,12$ \\
Sagittal size SC, mm & $15,9 \pm 0,97$ & $15,2 \pm 1,04$ & $14,1 \pm 0,87$ \\
IVD/SC & $0,97 \pm 0,05$ & $1,06 \pm 0,06$ & $1,16 \pm 0,07$ \\
& & & $P 3-1<0,05$ \\
ADS, mm & $3,7 \pm 0,45$ & $3,2 \pm 0,38$ & $2,1 \pm 0,26$ \\
& & & $P 2-1<0,01$ \\
& & $P 3-1<0,01$ \\
ADS/SC & $0,21 \pm 0,019$ & $0,15 \pm 0,017$ \\
& & & $P 3-2<0,05$ \\
\hline
\end{tabular}

(Reject - We) The sagittal size of the intervertebral disc (IVD), spinal canal (SC), anterior dural space (ADS), the ratio IVD/SC and $\mathrm{ADS} / \mathrm{SC}$ was calculated. The sagittal size of the $\mathrm{C} 2-\mathrm{C} 3$ disc in children aged 13-15 years averaged $15.6 \pm 0.8 \mathrm{~mm}, \mathrm{C} 3-\mathrm{C} 415.1 \pm 0.8 \mathrm{~mm}, \mathrm{C} 4-\mathrm{C} 514.6 \pm 0,7 \mathrm{~mm}, \mathrm{C} 5-$

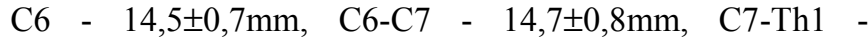
$14,5 \pm 0,7 \mathrm{~mm}$ was calculated, respectively. At the age of $16-$ 18 years, these parameters were $16,4 \pm 0,9 \mathrm{~mm}, 15,9 \pm 0,8 \mathrm{~mm}$, $15,4 \pm 0,8, \quad 15,3 \pm 0,7 \mathrm{~mm}, \quad 14,9 \pm 0,6 \mathrm{~mm}$ and $15,1 \pm 0.6 \mathrm{~mm}$ respectively.

In the I group of children, the average sagittal disc size was $15,4 \pm 0,98 \mathrm{~mm}$, in the II group - $16,1 \pm 1,07 \mathrm{~mm}$, in the III group - 16,3 $\pm 1,12 \mathrm{~mm}$, respectively. The parameters of average sagittal spinal size was $15,9 \pm 0,97 \mathrm{~mm}, 15,2 \pm 1,04 \mathrm{~mm}$, $14,1 \pm 0,87 \mathrm{~mm}$, respectively. The IVD/SC index was $0,97 \pm 0,05,1,06 \pm 0,06,1,16 \pm 0,07$, respectively. The ADS was $3,7 \pm 0,45 \mathrm{~mm}, 3,2 \pm 0,38 \mathrm{~mm}, 2,1 \pm 0,26 \mathrm{~mm}$, and ADS/SC $0,23 \pm 0,026,0,21 \pm 0,019,0,15 \pm 0,017$ respectively (table 2 ).

In healthy children without degenerative changes of the intervertebral discs, the anterior dural space on the ultrasonogram looks like a hypo-anechogenous zone with even edges - the front contour of which is bordered by the posterior edge of the fibrous ring and the posterior edge by the anterior margin of the spinal cord (Figure 1). When forming protrusions, the anterior dural space diminishes and deforms. The smallest width of the ADS is observed by median, circular and median-paramedian protrusion, and the greatest deformation of the spinal nerve canal is recorded by postero-lateral and paramedian protrusions (Figure 2-7).

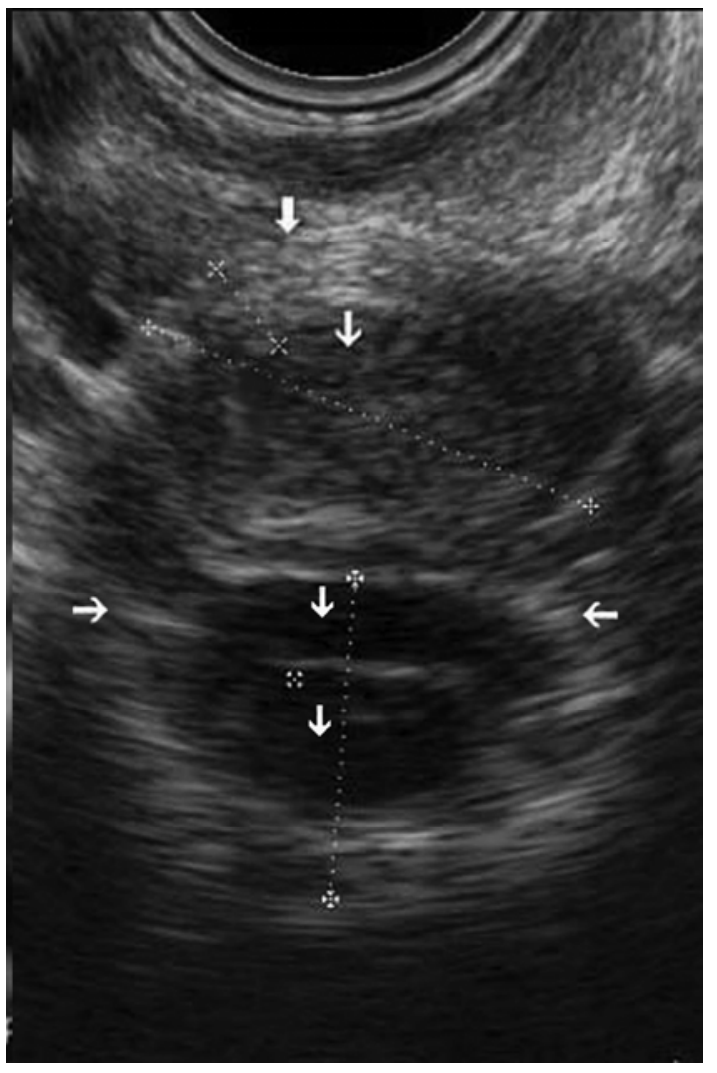

Figure 1. Cross sectional view of the intervertebral disc (IVD) and spinal canal (SC). Top- down arrows show fibrous ring (FR), the nucleus pulposus $(N P)$, anterior dural space (ADS), spinal cord. The horizontal arrows show canal of spinal nerves. 


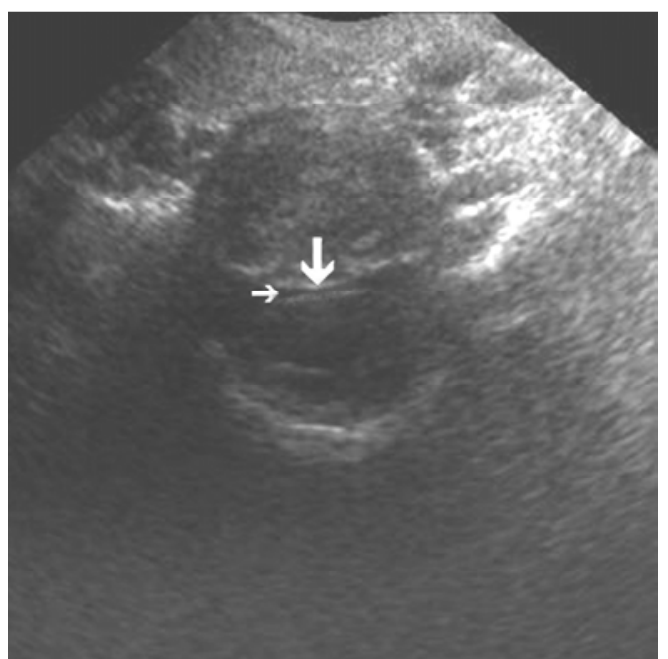

Figure 2. Median protrusion of the IVD (vertical arrow). The ADS is narrowing (horizontal arrow).

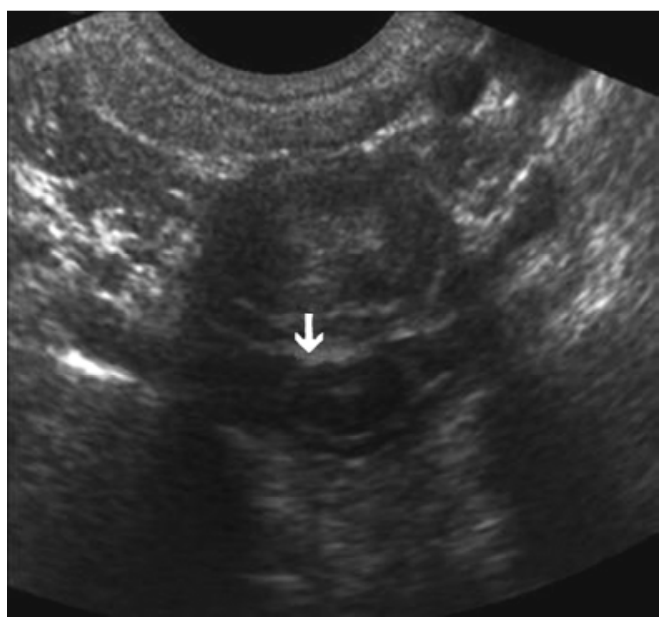

Figure 3. Median protrusion of the IVD (arrow). The ADS is not visualized and the anterior contour of the spinal cord is slightly deformed.

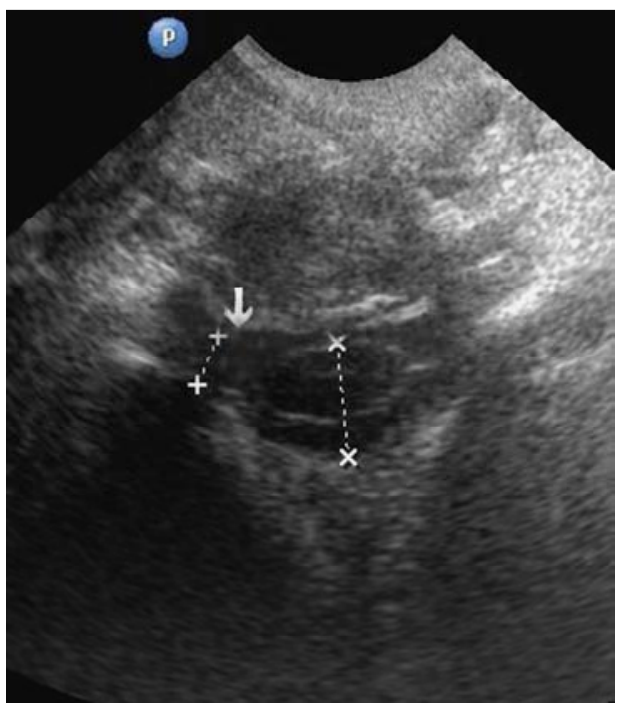

Figure 4. Right-sided median-paramedian protrusion. Narrowing of anterior dural space and right canal of spinal nerve (arrow).

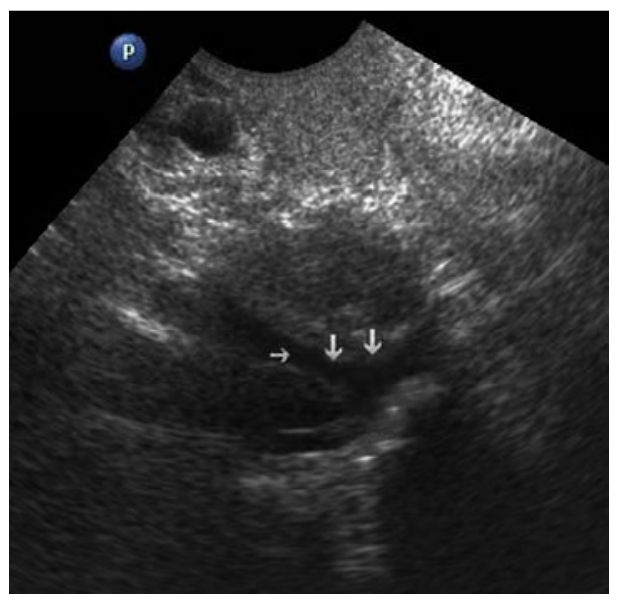

Figure 5. Left-side paramedian protrusion (vertical arrows). Anterior dural space is not chanced (horizontal arrow).

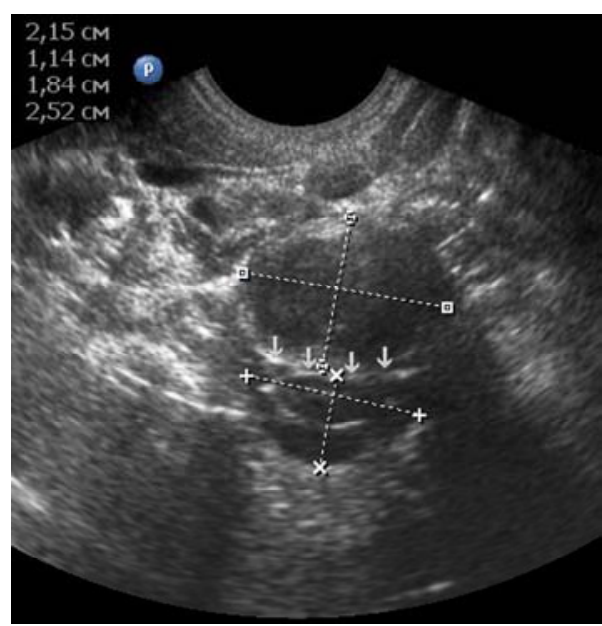

Figure 6. Circular protrusion (arrows).

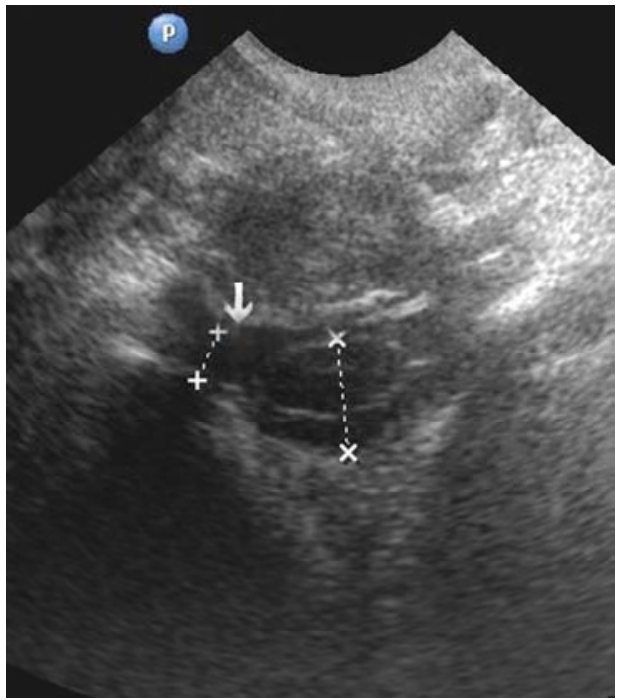

Figure 7. Right-side postero-lateral protrusion (arrow).

\section{Discussion}

As a result of the study, echographic features of protrusion of cervical intervertebral discs in adolescents were 
established. Mean parameters of the sagittal dimensions of the intervertebral discs, vertebral canal, anterior dural space, the ratio of the sagittal dimensions of the disc and the spinal canal, as well as the anterior dural space and the spinal canal were calculated. Different variants of localizations of protrusions are determined. Echographic parameters of children with degenerative changes in the pulpous nucleus (group II) and with protrusion of the discs (group III) were compared with the results of healthy children - without changes in the discs (group I).

In the course of the study, it was found that the most frequently observed paramedian $(37,7 \pm 5,8 \%)$, medianparamedian $(26,1 \pm 5,3 \%)$ and median $(23,2 \pm 5,1 \%)$ protrusions. The greatest sagittal size is observed with median and median-paramedian protrusions, which together were observed in $49.3 \%$ of cases. The same leads to the greatest decrease in the sagittal size of the anterior dural space, its deformation. Due to the fact that the degree of protrusion of the discs in the absence of rupture of the fibrous ring (ie without hernia) is small, there is no compression of the spinal cord. The greatest decrease in the anteriorposterior dimensions of the channels of the spinal cord nerves occurs with posterior-lateral and paramedian protrusions.

It is known that the most common method of examining the spine is radiography. However, the method does not allow visualizing intervertebral discs, spinal cord, spinal nerves, ligamentous apparatus. Radiography is radiationinduced.

Magnetic resonance imaging is the most accurate method for diagnosing the different stages of osteochondrosis in adults and children, but is expensive. When using highfrequency microconvex transducer, the echographic image of intervertebral discs and the spinal canal is not inferior in quality to magnetic resonance imaging. With ultrasound, patients do not receive radiation exposure. This indicates a great opportunity for echography, especially in pediatrics and use it as a screening study.

\section{Conclusions}

In adolescents in the cervical spine, median-paramedian and paramedian protrusions are most commonly found, which are most often localized at the level of both C5-C6 and $\mathrm{C} 4-\mathrm{C} 5$. The greatest narrowing of the anterior dural space is observed by median and median-paramedian protrusions, and the spinal nerve canal - by posterolateral and paramedian protrusions

\section{References}

[1] Czervionke L. Degenerative disc disease. In: Czervionke L, Fenton D. Imaging Painful Spinal Disorders, 1st ed. Philadelphia, PA: Elsevier Saunders; 2011; Chapter 17.

[2] De Bruin F, ter Horst S, van den Berg R, et al. Signal intensity loss of the intervertebral disc in the cervical spine of young patients on fluid sensitive. Skeletal Radiol. 2016; 45: 375-381.

[3] Teraguchi M, Yoshimura N, Hashizume H, et al. Prevalence and distribution of intervertebral disc degeneration over the entire spine in a population-based cohort: the Wakayama Spine Study. Osteoarthr Cartil. 2014; 22(1): 104-10.

[4] Robert E Windsor (2006). "Frequency of asymptomatic cervical disc protrusions". Cervical Disc Injuries. eMedicine. Retrieved 2008-02-27.].

[5] Deftereos SN, et al. (April-June 2009). "Localisation of cervical spinal cord compression by TMS and MRI". Funct Neurol. 24 (2): 99-105. PMID 19775538.

[6] Abdullaeiev R. Y., Khvisyuk A. N., Marchenko V. G. Ultrasonic tomography of the vertebral motor segment (book). Ukraine, Kharkov, "New word", 2008, 91p.

[7] Smith J, Finnoff JT. Diagnostic and interventional musculoskeletal ultrasound: Part 1. Fundamentals. Physical Medicine \& Rehabilitation. 2009; 1(1): 64-75. 2.

[8] Cameron, MH. Physical Agents in Rehabilitation: From Research to Practice, 3rd edition. Saunders, Philadelphia, PA; 2009].

[9] Javanshir K, Amiri M, Mohseni-Bandpei MA, Rezasoltani A, Fernández-de-las-Peñas $\mathrm{C}$. Ultrasonography of the cervical muscles: A critical review of the literature. Journal of Manipulative \& Physiological Therapeutics. 2010; 33(8): 630637]

[10] Abdullaiev R. Y, Bubnov R. V., Mammadov I. G., Abdullaiev R. R. Ultrasonography of herniated lumbar discs for screening programs in the late childhood and teenage. EPMA Journal 2013, 5 (Suppl 1): A 164. doi: 10.1186/1878-5085-5-S1-A164

[11] Spinal Ultrasonography. United Health care Commercial Medical Policy. Proprietary Information of United Health care. Copyright 2016 United HealthCare Services, Inc. Effective $08 / 01 / 2016$

[12] The Association for Medical Ultrasound Official Statement Page. http://www.aium.org/publications/statements.aspx. Updated October 31, 2015. Accessed February 20, 2017].

[13] Abdullaeiev R. Y., Khvisyuk A. N., Marchenko V. G. Echography in Neurology and Vertebrology (book). Ukraine, Kharkov, "Fact", 2017, 196p. 